\title{
Glomerular Procoagulant Activity in Human Proliferative Glomerulonephritis
}

\author{
P. G. Tipping, J. P. Dowling," and S. R. Holdsworth \\ Department of Medicine, Monash University, and ${ }^{*}$ Department of Tissue Pathology, Prince Henry's Hospital, Melbourne, Australia
}

\begin{abstract}
Mechanisms for initiation of glomerular fibrin deposition were studied using renal tissue obtained from two patients with rapidly progressive, crescentic glomerulonephritis. Histological examination showed extensive glomerular monocyte infiltration and fibrin deposition in both patients. Sonicated cell suspensions of isolated glomeruli from these patients contained markedly augmented levels of procoagulant activity (PCA) compared with the levels found in normal glomeruli. This PCA was characterized as tissue factor by its functional dependence on Factors VII and V, independence of Factors VIII and XII, inhibition by concanavalin $A$ and phospholipase $C$, and association with cell membranes. Its coagulant activity was also inhibited by a specific monoclonal anti-human tissue factor antibody. Tissue factor could be identified in glomeruli from these two patients by indirect immunofluorescence using this antibody. These studies implicate extrinsic pathway activation via tissue factor in intraglomerular deposition of fibrin in these patients. Activated monocytes, known to be a potent source of procoagulant activity and seen in large numbers within glomeruli from these patients, are a likely source of this tissue factor.
\end{abstract}

\section{Introduction}

Fibrin is a prominent mediator of injury in proliferative forms of human glomerulonephritis $(\mathrm{GN})^{1}(1,2)$. However, the mechanisms of glomerular fibrin deposition are unknown. Studies in experimental GN have provided some insights into this problem. Rats congenitally deficient in plasma prekallikrein and high molecular weight kininogen show no impairment of glomerular fibrin deposition associated with crescentic anti-glomerular basement membrane antibody induced GN (anti-GBM GN) (3). Further, in rabbits developing anti-GBM GN, Hageman Factor was not deposited with fibrin in the glomerular tuft, although passive leakage of Hageman Factor into Bowman's space could be identified (4). These studies suggest lack of involvement of contact activation of the intrin-

Address reprint requests to Dr. P. G. Tipping, Monash University, Department of Medicine, Prince Henry's Hospital, St. Kilda Road, Melbourne 3004, Australia.

Received for publication 7 October 1986 and in revised form 19 August 1987.

1. Abbreviations used in this paper: Anti-GBM GN, antiglomerular basement membrane antibody-induced glomerulonephritis; FR Ag, fibrinogen/fibrin-related antigen; F VIII C Ag, Factor VIII C antigen; GN, glomerulonephritis; PCA, procoagulant activity; TF, tissue factor; vWF, von Willebrand factor.

J. Clin. Invest.

(c) The American Society for Clinical Investigation, Inc.

0021-9738/88/01/0119/07 \$2.00

Volume 81, January 1988, 119-125 sic coagulation pathway in glomerular fibrin deposition in animals.

Experimental studies have demonstrated macrophage dependent glomerular fibrin deposition (5) and augmented glomerular procoagulant activity (PCA) (6-8) in anti-GBM GN in rabbits. Small amounts of tissue factor are present in the renal cortex of normal rabbits (9) and normal rat glomeruli also contain PCA with the functional properties of tissue factor (10). Rabbits developing anti-GBM GN were found to have augmented glomerular PCA of a complex nature, which varied as the disease progressed (7). Other studies have described increased glomerular PCA with the functional characteristics of tissue factor, in various macrophage-dependent models of rabbit $\mathrm{GN}(6,8)$.

There is less known about the mechanisms of glomerular fibrin deposition in human GN. Hoyer et al. (11) found glomerular fibrin deposition in association with von Willebrand factor (vWF) in patients with hyperacute renal homograft rejection, hemolytic uremic syndrome and postpartum renal failure, however in patients with severe proliferative $G N$ with crescents, glomerular fibrin deposition was seen in the absence of vWF. This suggested different mechanisms of fibrin deposition may be involved. Proliferative crescentic GN is now known to be associated with prominent glomerular macrophage infiltration (12-15).

Monocytes and tissue macrophages express a membrane bound procoagulant activity with the functional characteristics of tissue factor (16-20). Its expression is augmented by various stimuli (16, 21-25). Circulating monocytes from patients with lupus nephritis express markedly augmented PCA with prothrombinase properties (26). In experimental GN, a close temporal relationship between glomerular macrophage infiltration and fibrin deposition was observed, in association with markedly augmented levels of glomerular PCA (6). Macrophage depletion and repletion studies have demonstrated that both glomerular fibrin deposition and augmented glomerular PCA are dependent on the presence of glomerular macrophages (5).

Functional studies of the quantity and nature of PCA in glomeruli from patients with proliferative GN have not previously been reported. The availability of tissue from two patients with rapidly progressive crescentic $\mathrm{GN}$, who died from respiratory failure within a few days of diagnosis and before receiving substantial immunosuppressant therapy, provided a unique opportunity to study glomerular PCA in human GN.

\section{Methods}

\section{Source of human renal tissues}

Human renal tissue was obtained at postmortem from two patients who died from acute crescentic GN.

Patient 1 was a 17 -yr-old female, who presented with hemoptysis and oliguria due to acute GN. Anti-GBM antibodies were present in her serum. Over the next $24 \mathrm{~h}$, hemoptysis and pulmonary infiltration necessitated intubation and ventilatory support. Anuria with a serum creatinine of $1,151 \mu \mathrm{m} /$ liter required institution of hemodialysis. De- 
spite these measures together with prednisolone $3 \mathrm{~g}$, cyclophosphamide $655 \mathrm{mg}$, and plasma exchange of 10 liters, she died of respiratory failure $72 \mathrm{~h}$ later. Renal tissue obtained at postmortem revealed a proliferative, crescentic GN, with linear basement membrane deposition of IgG, confirming the diagnosis of anti-GBM antibody mediated Goodpasture's syndrome.

Patient 2 was an 81-yr-old man who presented with pleuritic chest pain and cough. His chest $x$-ray revealed diffuse pulmonary infiltrates and urine analysis demonstrated proteinuria of $1.5 \mathrm{~g} / 24 \mathrm{~h}$, hematuria, and granular casts. In hospital, his creatinine progressively rose from $180 \mu \mathrm{m} /$ liter on admission to a peak of $960 \mu \mathrm{mol} /$ liter. A renal biopsy demonstrated a crescentric $\mathrm{GN}$ with granular mesangial deposition of immunoglobulin within glomeruli, suggesting immune complex initiated GN. Treatment with prednisolone $0.5 \mathrm{~g}$ and cyclophosphamide $150 \mathrm{mg}$ was commenced but the patient died unexpectedly $24 \mathrm{~h}$ later.

Renal tissue was also obtained at postmortem from six age- and sex-matched patients with no clinical or histological evidence of renal disease.

\section{Histological assessment}

Routine histology was performed on tissue obtained at renal biopsy, fixed in $10 \%$ neutral buffered formalin, embedded in paraffin and stained with periodic acid Schiff, hematoxylin and eosin and silver methenamine-Masson's trichrome.

Immunofluorescence was performed on $4-\mu \mathrm{m}$ frozen tissue sections from both patients and normal human kidney controls. Controls with second antibody alone were performed when indirect immunofluorescence was used.

Fibrin-related antigen (FR Ag) was demonstrated by staining with fluorescein-conjugated rabbit anti-human fibrinogen antiserum (Dako, Copenhagen, Denmark).

vWF was demonstrated by indirect immunofluorescence using goat anti-human vWF (Miles Scientific, Naperville, IL) and fluorescein-conjugated rabbit anti-goat IgG antiserum (Sigma Chemical Co., St. Louis, MO), which was absorbed against human red blood cells immediately before use. This polyclonal anti-human vWF antiserum markedly prolonged the partial thromboplastin time with kaolin (PTTK) of recalcified citrated normal human plasma, indicating cross-reactivity with Factor VIII C antigen (F VIII C Ag).

F VIII C Ag. A specific mouse monoclonal anti-human F VIII C Ag antiserum (RPAH 24-2-C7, Dr. D. Joshua, Sydney, Australia) was used to stain for F VIII $\mathrm{C} \mathrm{Ag}$ by indirect immunofluorescence as previously described (27). The second antibody (fluorescein conjugated sheep anti-mouse IgG, Silenus Laboratories, Ferntree Gully, Victoria) was absorbed against human red blood cells immediately before use. Fresh frozen human liver tissue was used as a positive control.

Tissue factor $(T F)$. Staining for TF was performed with a specific mouse monoclonal anti-human TF antibody (HTF1-7B8, Dr. S. Carson, Denver, $\mathrm{CO}$ ). This antibody has been previously characterized and shown to inhibit the functional activity of human TF (28). The second antibody was used as described for F VIII C Ag.

Glomerular macrophages were demonstrated by nonspecific esterase staining of 4- $\mu \mathrm{m}$ frozen cut tissue sections according to the method of Yam (29). Infiltrating glomerular mononuclear cells were also identified by electronmicroscopy in $2.5 \%$ gluteraldehyde fixed, araldite embedded tissue. Ultra-thin sections were stained with uranyl acetate and lead citrate and viewed in an electronmicroscope Philips 300; Philips Electronic Instruments, Inc., Mahwah, $\mathrm{NJ}$ at an accelerating voltage of $80 \mathrm{kV}$.

\section{Immunoglobulin and complement}

Staining for IgG, IgA, IgM, C3, Clq, and C4 was performed on 4- $\mu \mathrm{m}$ sections of frozen tissue by routine direct immunofluorescence, using polyclonal, rabbit anti-human antisera.

\section{Measurement of glomerular PCA}

The graded sieving technique $(6,12)$ was used to prepare isolated glomeruli from the postmortem cortical renal tissue. Glomerular prep- arations were washed in PBS and purity of the preparation and number of glomeruli was checked by phase-contrast microscopy. Preparations were adjusted to a concentration of $10^{4}$ glomeruli/ml of PBS, and stored at $-20^{\circ} \mathrm{C}$. Glomeruli were disrupted by sonication before assay $(\times 10,1 \mathrm{~s}$ bursts) using a sonifier cell disruptor (B30; Branson Sonic Power Co., Danbury, CT) to form glomerular lysates. PCA was assayed using a standard one stage clotting assay $(5,6,8)$. Glomerular lysate $(100 \mu \mathrm{l})$ was prewarmed at $37^{\circ} \mathrm{C}$ for $3 \mathrm{~min}$, together with $100 \mu \mathrm{l}$ of $0.025 \mathrm{M}$ calcium chloride, in $76 \times 9 \mathrm{~mm}$ polystyrene tubes. Citrated normal human plasma (Citrol level 1 control; Dade Diagnostics, Aguada, Puerto Rico) $(100 \mu \mathrm{l})$, prewarmed to $37^{\circ} \mathrm{C}$, was then forcibly added and the clotting time determined by the manual tilt method. All lysates were assayed in triplicate and diluted 1 in 10 where necessary. A value for the PCA was derived by comparison of the clotting times with the coagulant activity of standard rabbit thromboplastin (Sigma Chemical Co.). $100 \mu$ lof standard was assigned a value of $1,000 \mathrm{mU}$ of PCA. The activity of the standard was assayed in triplicate and was found to be linear on a $\log / \log$ plot of clotting time against units of PCA over the range from $0.1 \mathrm{mU}$ to $100 \mathrm{mU}$. The PCA of glomerular lysates was expressed as $\mathrm{mU} / 10^{3}$ glomeruli.

To determine the concentration of PCA per milligram of protein in purified glomeruli and whole cortical tissue; homogenates of these tissues were extensively sonicated to totally disrupt tissue architecture, (confirmed by phase-contrast microscopy). The PCA content of these homogenates was assayed as previously described, and the protein content determined by the Lowry method (30). Glomerular assays were performed in duplicate and four separate cortical samples were assayed from each patient.

Although the graded sieving technique allows purification of glomeruli from cortex, cortical tissue free of glomeruli could not be obtained from these frozen tissues by this or any other technique. Therefore, the number of glomeruli per milligram of cortical tissue was determined by counting glomeruli in hematoxylin and eosin-stained serial sections of cortical tissue of known weight. These estimations were performed on three separate pieces of tissue for each patient, and allowances for their glomerular content were made when determining the PCA of cortical tissue.

\section{Characterization of glomerular PCA}

Factor-deficient plasma. Factor-deficient human plasmas were used to determine the factor dependency of the glomerular PCA. The following reconstituted lyophilized plasmas were used: $(a)$ Congenital Factor VII-deficient plasma (Factor VII activity $<2 \%$ of normal human levels). (b) Congenital Factor VIII deficient plasma, General Diagnostics, Morris Plains, NJ. (c) Aged Factor V-deficient plasma from Sigma Chemical Co. (Factor V activity $<1 \%$ of normal human plasma). (d) Congenital Factor XII-deficient plasma (General Diagnostics). Glomerular lysates were assayed for PCA in these factor-deficient sera using the manual tilt method as previously described, and the result compared to the activity in normal human plasma (Citrol).

Effect of concanavalin $A$. Glomerular lysates $(100 \mu \mathrm{l})$ were incubated before assay with concanavalin A, (Pharmacia Fine Chemicals, Uppsala, Sweden) $100 \mu \mathrm{g}$ in $100 \mu 1$ of $0.9 \%$ saline for $30 \mathrm{~min}$ at $20^{\circ} \mathrm{C}$. Incubations were also performed with concanavalin $A$ in the presence of 100 -fold excess (by weight) of $\alpha$-methyl-D-mannoside (Sigma Chemical Co.). Controls, incubated with saline alone, were included.

Effect of phospholipase C. Phospholipase C type III from Bacillus cereus (Sigma Chemical Co.) $(1 \mathrm{U} / \mathrm{ml})$ was dissolved in veronal saline buffer containing $1.0 \mathrm{mM} \mathrm{ZnSO}_{4}$. Glomerular lysates $(100 \mu \mathrm{l})$ were incubated with phospholipase $\mathrm{C}(100 \mu \mathrm{l})$ or buffer alone at $37^{\circ} \mathrm{C}$ for 15 min before assay of PCA.

Ultracentrifugation of glomerular lysates. Pooled sonicated glomerular lysates were spun at $165,000 \mathrm{~g}$ for $1 \mathrm{~h}$ at $4^{\circ} \mathrm{C}$ in an ultracentrifuge (Sorvall, Norwalk, CT). The resultant pellet was reconstituted to its original volume with PBS; and both the pellet and the supernatant were assayed for PCA. The PCA recovered in each fraction was compared with the PCA of the original lysate. 


\section{Immunological inhibition studies}

Functional inhibition studies were performed using the monoclonal anti-human TF antibody (HTF1-7B8) and the anti-human F VIII C Ag antiserum (RPAH 24-2-C7). Glomerular lysates (100 $\mu \mathrm{l})$ from both patients were preincubated with serial dilutions of either antibody (10 $\mu \mathrm{l})$, an irrelevant mouse monoclonal antibody $(10 \mu \mathrm{l})$ or $\operatorname{PBS}(10 \mu \mathrm{l})$ for $30 \mathrm{~min}$ at $21^{\circ} \mathrm{C}$ before assay for PCA as previously described. All incubations and assays were performed in triplicate.

\section{Results}

\section{Histological assessment}

Light microscopy revealed a crescentic GN involving $100 \%$ of glomeruli in patient 1 with a sparse interstitial mononuclear cell infiltrate (Fig. 1 a). Nonspecific esterase demonstrated prominent glomerular staining consistent with the presence of glomeruli in patient 1 with a sparse interstitial mononuclear cells (Fig. $1 b$ ). A mean of 19 esterase positive cells were seen per glomerular cross-section. Immunofluorescence showed bright linear staining for IgG on the glomerular basement membrane. There was no staining for IgA or IgM and no staining of tubular basement membranes. Slight granular mesangial staining for $\mathrm{C} 3$ was seen, but $\mathrm{Clq}$ and $\mathrm{C} 4$ were both negative. Bright staining for $\mathrm{F} \mathrm{R} \mathrm{Ag}$ was present in all glomeruli (Fig. $1 \mathrm{c}$ ), and positive glomerular staining for TF was observed to a dilution of 1:160 of the anti-TF antibody (Fig. 1 d). Other renal structures were not stained. Staining for vWF was positive in some intrarenal vessel walls but glomerular staining was no different from that seen in normal tissues. Staining for F VIII C Ag was positive in normal human liver, but could not be detected in any renal structures.

A diffuse proliferative GN with $70 \%$ crescent formation and some interstitial mononuclear cell infiltrate was seen in patient 2 (Fig. $2 a$ ). Nonspecific esterase staining indicated that monocytes (mean, eight cells per glomerular cross-section) were present within glomerular capillary loops (Fig. 2 b), and were sparsely present within the interstitium. Cells with the typical ultrastructural appearances of macrophages were prominent within capillary loops and crescents. There was granular deposition of IgG in the mesangium and capillary
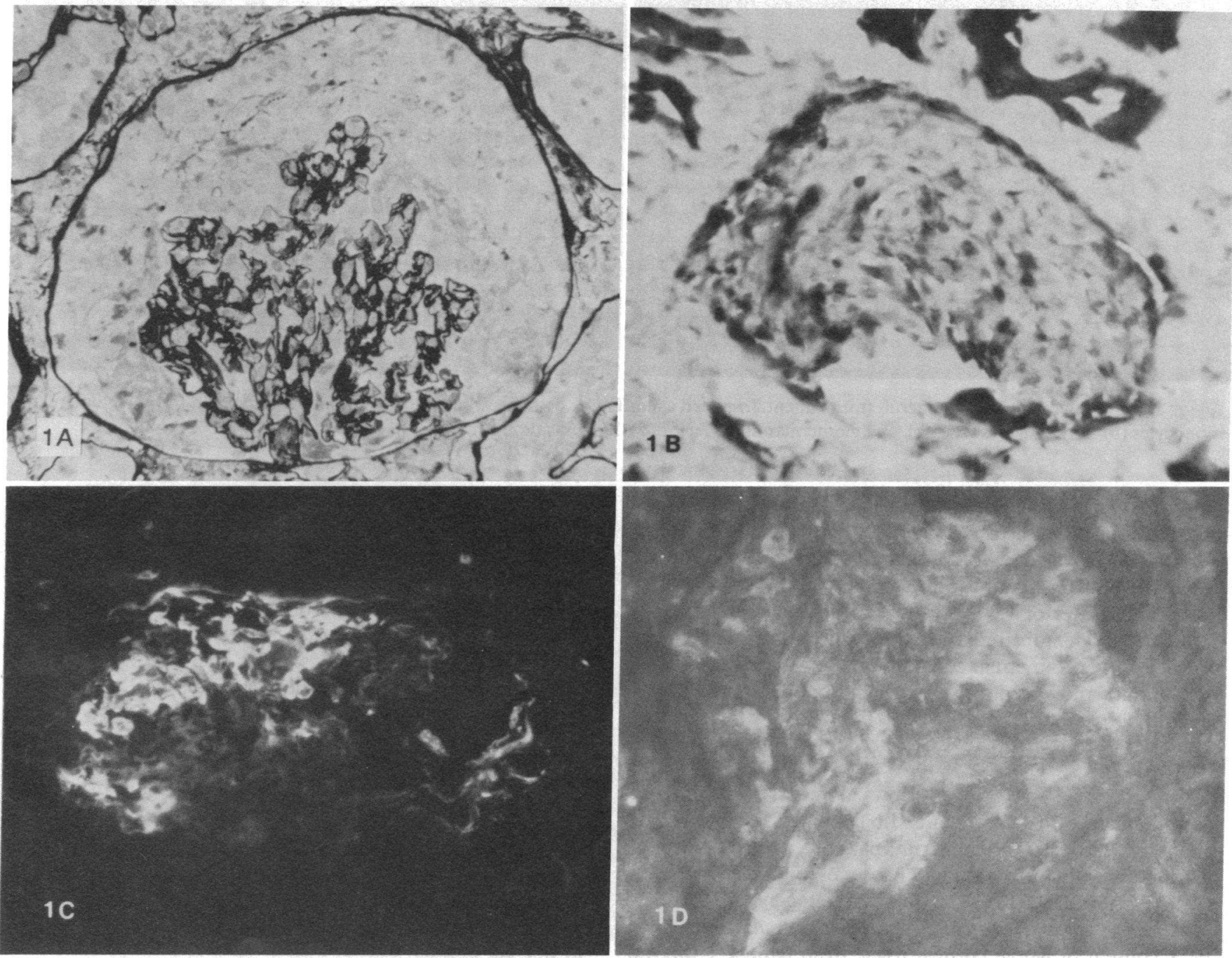

Figure 1. Photomicrographs of glomeruli from patient 1 demonstrating a cellular glomerular crescent and compressed glomerular tuft, (Silver methenamine-Masson's trichrome stain); (a) numerous monocytes within the glomerular tuft and forming a crescent, with positive staining also in tubular cells (nonspecific esterase), (b) glomerular F R Ag (direct immunofluorescence) (c) and glomerular tissue factor. (Indirect immunofluorescence) $(d)$ Magnification $\times 250$. 

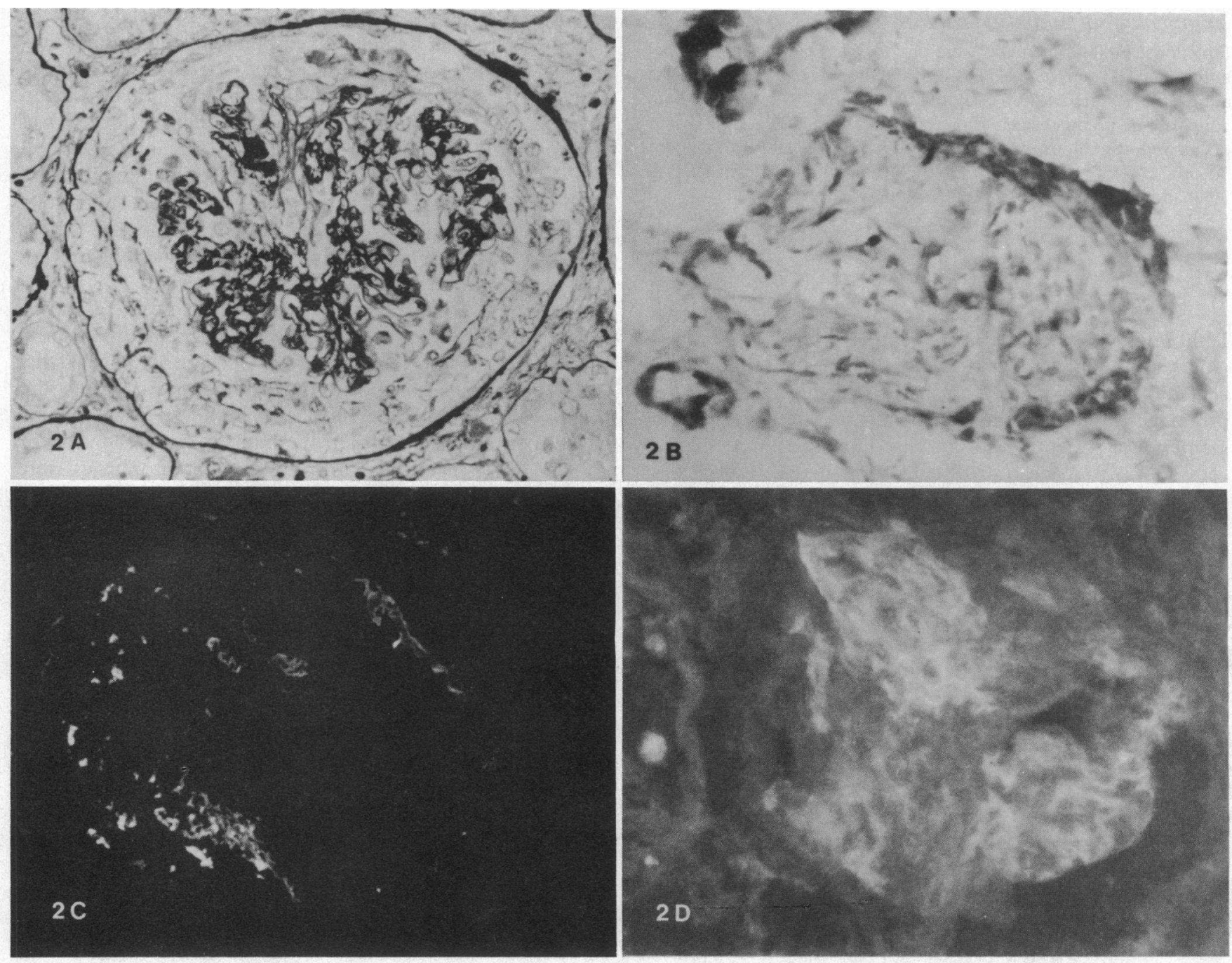

Figure 2. Photomicrographs of glomeruli from patient 2, stained as for Fig. 1, demonstrating a cellular glomerular crescent (a) intraglomerular monocytes $(b)$, glomerular $\mathrm{F} \mathrm{R} \mathrm{Ag}(c)$, and glomerular tissue factor $(d)$. Magnification $\times 250$.

loops, and faint staining for IgA or IgM. Staining for C3 was positive in a similar distribution to IgG. Clq and $\mathrm{C} 4$ were both negative. F R Ag was prominent in capillary loops of most glomeruli (Fig. $2 c$ ), and specific glomerular TF staining was positive to a titer of 1:80, (Fig. $2 d$ ). vWF and F VIII C Ag could not be demonstrated in glomeruli by immunofluorescence. Positive glomerular staining for TF was seen in normal renal tissues and was positive to an end point titer of 1:20 of the anti-TF antibody.

\section{Glomerular PCA}

Glomerular PCA levels. Fig. 3 shows glomerular lysates from both patients with GN contained augmented levels of PCA; patient $1,220 \mathrm{mU} / 10^{3}$ glomeruli; patient $2,10 \mathrm{mU} / 10^{3}$ glomeruli) compared to glomerular lysates of normal human kidneys. (PCA, $0.2 \pm 0.03 \mathrm{mU} / 10^{3}$ glomeruli; mean \pm SEM).

Glomerular and cortical tissue PCA concentrations. The PCA content of whole cortical tissue from patient 1 was 4.0 $\mathrm{mU} / \mathrm{mg}$, and this tissue contained 17 glomeruli/mg by histological assessment. Therefore, after allowance for the glomerular PCA contribution (17 glomeruli/mg, $0.22 \mathrm{mU}$ PCA/glomerulus), the nonglomerular cortical tissue PCA was esti- mated to be $0.3 \mathrm{mU} / \mathrm{mg}$. Purified glomeruli from patient 1 contained $42.4 \mathrm{mU} / \mathrm{mg}$ of PCA, indicating that PCA was 140 times more concentrated in glomeruli than in other cortical structures. Similarly with patient 2 , the PCA of whole cortex (10 glomeruli $/ \mathrm{mg}$ ) was $0.34 \mathrm{mU} / \mathrm{mg}$, giving a specific nonglomerular PCA concentration of $0.24 \mathrm{mU} / \mathrm{mg}$. The PCA of purified glomeruli this patient was $12.8 \mathrm{mU} / \mathrm{mg}$, i.e., 53 times more concentrated than nonglomerular cortical tissue. Normal cortical tissue contained $<0.01 \mathrm{mU} / \mathrm{mg}$ of PCA.

\section{Characterization of glomerular PCA}

$P C A$ in factor-deficient plasma. The results for glomerular PCA assayed in normal and congenital factor deficient plasmas are shown in Table I. Glomerular lysates from both normal and nephritic kidneys showed marked dependence on Factors V and VII for expression of their functional activity. PCA in Factor V-deficient plasma was $<0.1 \%$ of the activity in normal plasma, and in Factor VII-deficient plasma, PCA ranged from 5 to $0.1 \%$ of normal. Deficiency of Factors VIII and XII did not diminish the expression of glomerular PCA in either normal or nephritic glomeruli.

Effect of concanavalin A. In Table II concanavalin A inhib- 


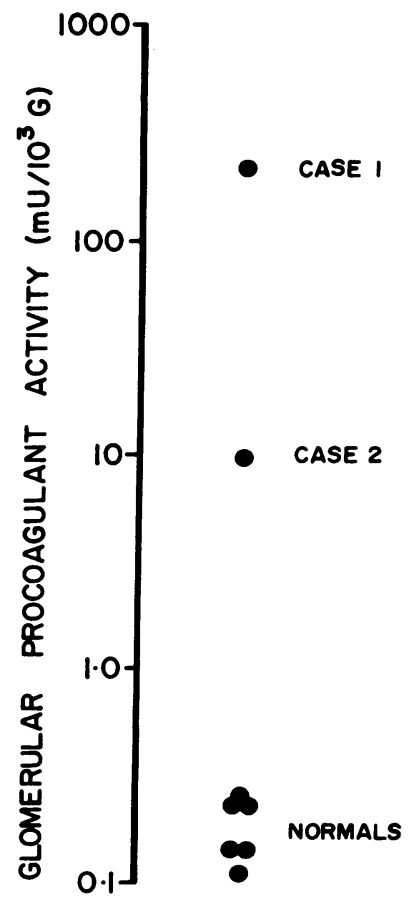

Figure 3. PCA in glomerular lysates from patients 1 and 2 , and six normal patients.

ited the expression of PCA in all glomerular lysates to a similar extent to its ability to inhibit standard rabbit brain thromboplastin; patient $1,77 \%$ inhibition; patient $2,89 \%$ inhibition; controls, $83 \pm 3 \%$ inhibition. This inhibition was abolished by preincubation in concanavalin A together with $\alpha$-methyl mannoside.

Effect of phospholipase $C$. Preincubation with phospholipase C completely abolished the expression of PCA in glomerular lysates, in both nephritic and normal glomeruli (Table II). (All tubes failed to clot after $500 \mathrm{~s}$ ).

Ultracentrifugation of glomerular lysates. After ultracentrifugation, the PCA of glomerular lysates was recovered in the cell membrane pellet; patient $1,88 \%$; patient $2,80 \%$; controls, $85 \pm 5 \%$. Measurable amounts of PCA were not detectable in the supernatant fraction (PCA $<1 \%$ of original activity in each case).

\section{Immunological inhibition of glomerular PCA}

Incubation with anti-TF antibody markedly inhibited the functional expression of PCA in glomerular lysates from both patients (Fig. 4). In patient 1, 12 ng of antibody caused $43 \%$ inhibition, and $120 \mathrm{ng}$ resulted in $90 \%$ inhibition of glomerular PCA activity. In patient 2,12 ng caused $63 \%$ inhibition and $120 \mathrm{ng} 90 \%$ inhibition of glomerular PCA activity.

Table I. Glomerular PCA in Factor Deficient Human Plasma (\% Activity in Normal Human Plasma)

\begin{tabular}{lllll}
\hline & \multicolumn{4}{l}{ Factor deficiency } \\
\cline { 2 - 5 } & $\mathrm{V}$ & VII & VIII & XII \\
\hline Patient 1 & 0.1 & 5.5 & 150 & 150 \\
Patient 2 & $<0.1$ & 1.2 & 110 & 150 \\
Normals & $<0.1$ & $0.1 \pm 0.1$ & $140 \pm 40$ & $150 \pm 30$ \\
\hline
\end{tabular}

Table II. Inhibition of Glomerular PCA by Concanavalin A and Phospholipase C (Inhibition, \% Control)

\begin{tabular}{lll}
\hline & Concanavalin A & Phospholipase C \\
\hline & $1 \mathrm{mg} / \mathrm{ml}$ & $1 \mathrm{U} / \mathrm{ml}$ \\
Patient 1 & 77 & $>99$ \\
Patient 2 & 89 & $>99$ \\
Normals & $83 \pm 3$ & $>99$
\end{tabular}

Incubation with anti-F VIII $\mathrm{C} \mathrm{Ag}$ antiserum or an irrelevant mouse monoclonal antibody caused no inhibition of glomerular PCA activity.

\section{Discussion}

Prominent glomerular fibrin deposition is seen in the most aggressive forms of human GN, particularly in crescentic GN $(1,2)$. Fibrin appears to be an important mediator of injury in that its deposition parallels the development of crescents and renal failure and defibrination of experimental animals preserves renal function $(31,32)$. The pathogenic mechanisms responsible for glomerular fibrin deposition are unknown. Platelets do not appear to a prominent participant in human GN (33).

Intrinsic coagulation pathway activation via tissue factor expressed on macrophage surface membranes (macrophage PCA) is a potent stimulus for fibrin formation at inflammatory sites $(34,35)$. The ability of macrophages to initiate glomerular fibrin deposition has been demonstrated in an experimental model of anti-GBM GN (5). Augmented glomerular PCA with the functional characteristics of tissue factor is associated with glomerular macrophage infiltration and fibrin deposition in experimental macrophage dependent models of $\mathrm{GN}$, but has never previously been demonstrated in human GN.

The current studies clearly demonstrate the presence of augmented PCA with the functional and immunological characteristics of macrophage PCA (tissue factor) in glomeruli from two patients with crescentic GN. Low levels of tissue factor were present in normal glomeruli. Histological studies of renal tissue from both these patients revealed a prominent mononuclear cell infiltrate, glomerular fibrin deposition, and enhanced tissue factor staining in glomeruli. Glomerular vWF and F VIII C Ag could not be demonstrated by immunofluorescence. These findings are consistent with glomerular fibrin deposition initiated by activation of the extrinsic pathway.

Augmentation of glomerular PCA compared to normal was 1,000 -fold in patient 1 with $100 \%$ of glomeruli with crescents, and 50-fold in patient 2 , who had histologically fewer glomerular macrophages. These patients appeared to have dif-

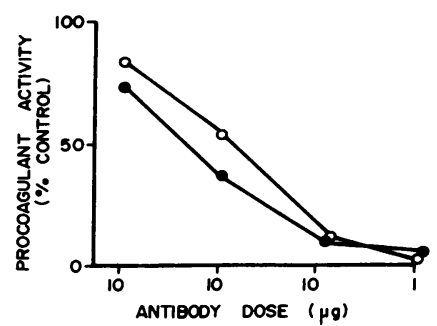

Figure 4. Inhibition curves for glomerular PCA from both patients, incubated with serial dilutions of monoclonal antihuman TF antibody. (Patient 1, closed circles; patient 2, open circles.) 
ferent pathogenetic mechanisms for initiation of their glomerular injury. Patient 1 had anti-GBM antibody initiated GN, whereas the pattern of deposition of immune reactants in the glomeruli from patient 2 suggested an immune complex initiated GN. Differences between the sites, quantities, and subclasses of deposited immunoglobulin in these two patients may potentially contribute to differential macrophage activation, and augmentation of PCA expression. This, together with different glomerular macrophage numbers, may account for the variation in augmentation of glomerular PCA between the two patients.

The PCA of renal tissue from both patients was highly concentrated in glomeruli. This was confirmed by both functional and histological assessment. The high concentration of PCA within glomeruli is consistent with an important role for this initiator of the extrinsic pathway in local glomerular fibrin deposition. Cortical tissue from these patients also contained some augmented PCA compared to normals on functional but not histological assessment. This augmented cortical PCA was found in low concentration and may be attributable to the sparse interstitial macrophage infiltrate seen in both patients.

Glomerular PCA in both normal and diseased kidneys had similar functional characteristics. Its activity was dependent on the presence of Factors VII and V, but largely independent of Factors VIII and XII, indicating that it initiates the extrinsic coagulation pathway, consistent with tissue factor.

Glomerular PCA was inhibited by concanavalin A, and the specific nature of this inhibition was confirmed by the ability of the conjugate sugar $\alpha$-methyl-mannoside to block this effect. This is also consistent with tissue factor, a membrane bound glycoprotein (19) that is functionally inhibited when bound to concanavalin $\mathrm{A}(36,37)$.

Close association with certain membrane phospholipids is also essential for the functional activity of tissue factor. This explains the ability of phospholipase $\mathrm{C}$ to destroy its activity (38). The functional activity of glomerular PCA was also completely destroyed after incubation with phospholipase $\mathrm{C}$. The coagulant activity of glomerular PCA was found in the cell membrane fraction after sonication and ultracentrifugation. These studies are also consistent with glomerular PCA being tissue factor. Finally, the functional inhibition of glomerular PCA by a specific monoclonal anti-tissue factor antibody provides clear evidence that augmented glomerular PCA in these patients is tissue factor.

Macrophages, known to be a potent source of tissue factor were prominent in the glomerular lesions of both these patients. They are the most likely source for the augmented PCA. Other inflammatory cells such as neutrophils and lymphocytes do not express PCA $(16,17)$. Intrinsic glomerular cells have not been shown to express PCA, although under certain culture conditions endothelial cells may express low levels of tissue factor that can be augmented by interleukin $1(39,40)$. Therefore, the potential exists for macrophages to also augment glomerular PCA by the effects of interleukin 1 on glomerular endothelial cells.

In summary, two patients with proliferative, crescentic GN and prominent intraglomerular fibrin deposition were shown to have augmented PCA with the functional and immunological characteristics of tissue factor. Macrophages, abundantly present in these glomerular lesions, are a likely source of this augmented tissue factor. This suggests that glomerular fibrin deposition in human proliferative $\mathrm{GN}$ may be due to extrinsic pathway activation by macrophage tissue factor, and would be consistent with macrophage-dependent glomerular fibrin deposition observed in experimental GN.

\section{Acknowledgments}

The expert technical assistance of Mr. Gary Chan, Miss C. Smith, and Mrs. M. McKimmie is gratefully acknowledged. Monoclonal antihuman tissue factor antibody (HTF1-7B8) was generously donated by Dr. Steven Carson, Department of Pathology, University of Colorado, Health Sciences Center, Denver, CO. Monoclonal Anti-human Factor VIII C Ag (RPAH 24-2-C7) was generously donated by Dr. D. Joshua, Department of Haematology, Royal Prince Alfred Hospital, Camperdown, N.S.W., Australia.

These studies were supported by the National Health and Medical Research Council of Australia and the Australian Kidney Foundation. Dr. Tipping is an NH and MRC Senior Research Officer.

\section{References}

1. Kincaid-Smith, P. 1972. Coagulation and renal disease. Kidney Int. 2:183-190.

2. McCluskey, R. T., P. Vassalli, G. Gallo, and D. S. Baldwin. 1966. An immunofluorescent study of pathogenic mechanisms in glomerular diseases. $N$. Engl. J. Med. 274:695-701.

3. Villaro, J., P. Errasti, M. Goni, A. Monzo, A. Purroy, and A. Sanchez-Ibarrola. 1984. Pathogenesis of glomerular fibrin deposition: Role of the contact system. Kidney Int. 26:219. (Abstr.)

4. Wiggins, R. G. 1985. Hageman factor in experimental nephrotoxic nephritis in the rabbit. Lab. Invest. 53:335-348.

5. Holdsworth, S. R., and P. G. Tipping. 1985. Macrophage induced glomerular fibrin deposition in experimental glomerulonephritis in the rabbit. J. Clin. Invest. 76:1367-1374.

6. Tipping, P. G., and S. R. Holdsworth. 1986. The participation of macrophages, glomerular procoagulant and Factor VIII in glomerular fibrin deposition. Studies in anti-GBM antibody induced glomerulonephritis in rabbits. Am. J. Pathol. 124:10-17.

7. Wiggins, R. C., A. Galtfelter, and J. Brukman. 1985. Procoagulant activity in glomeruli and urine of rabbits with nephrotoxic nephritis. Lab. Invest. 53:156-165.

8. Tipping, P. G., and S. R. Holdsworth. 1987. Quantitation and characterization of glomerular procoagulant activity in experimental glomerulonephritis. Lab. Invest. 56:151-154.

9. Glas, P., and T. Astrup. 1970. Thromboplastin and plasminogen activation in tissues of the rabbit. Am. J. Physiol. 219:1140-1146.

10. De Prost, D., and A. Kanfer. 1985. Quantitative assessment of procoagulant activity of isolated rat glomeruli. Kidney Int. 28:566568.

11. Hoyer, J. R., A. F. Michael, and L. W. Hoyer. 1974. Immunofluorescent localization of antihaemophiliac factor antigen and fibrinogen in human renal diseases. J. Clin. Invest. 53:1375-1384.

12. Atkins, R. C., S. R. Holdsworth, E. F. Glasgow, and F. E. Matthews. 1976. The macrophage in human rapidly progressive glomerulonephritis. Lancet. i:830-832.

13. Monga, G., G. Mazzucco, G. B. Barbiano di Belgiojoso, and G. Busnach. 1979. The presence and possible role of monocyte infiltration in human chronic proliferative glomerulonephritides. Light microscopic, immunofluorescence and histochemical correlation. Am. J. Pathol. 94:271-284.

14. Ferrario, F., A. Castiglione, G. Colasanti, G. Barbiano di Belgiojoso, S. Bertoli, and G. D'Amico. 1985. The detection of monocytes in human glomerulonephritis. Kidney Int. 28:513-519.

15. Magil, A. B., and A. B. Wadsworth. 1981. Monocytes in human glomerulonephritis. An electromicroscopic study. Lab. Invest. 34:7781.

16. Rivers, R. P. A., W. E. Hathaway, and W. L. Weston. 1975. 
Endotoxin induced coagulant activity of human monocytes. Br. $J$. Haematol. 30:311-316.

17. Edwards, R. L., F. R. Rickles, and A. M. Bolorove. 1979. Mononuclear cell tissue factor. Cell of origin and requirements for activation. Blood. 54:359-370.

18. Rothberger, H., F. B. Dove, T. K. Lee, M. P. McGee, and B. Karden. 1983. Procoagulant activity of lymphocyte-macrophage populations in rabbits. Selective increases in marrow, blood and spleen cell during Schwartzman reactions. Blood. 61:712-717.

19. Zeldis, S. M., Y. Nemerson, and F. A. Pitlick. 1971. Tissue factor (thromboplastin). Localization to plasma membranes by peroxidase conjugated antibodies. Science (Wash. DC). 55:175-179.

20. Rothberger, H., M. P. McGee, and T. K. Lee. 1984. Tissue factor activity; a marker of alveolar macrophage maturation in rabbits. Effects of granulomatous pneumonitis. J. Clin. Invest. 73:1524-1531.

21. Helin, H., and T. S. Edgington. 1983. Allogenic induction of the human $\mathrm{T}$ cell instructed monocyte procoagulant response is rapid and is elicited by HLA-DR. J. Exp. Med. 158:962-975.

22. Gregory, S. M., and T. S. Edgington. 1985. Tissue factor induction in human monocytes. Two distinct mechanisms displayed by different alloantigen-responsive T cell clones. J. Clin. Invest. 76:24402445.

23. Schwartz, B. S., and T. S. Edgington. 1981. Immune complexinduced human monocyte procoagulant activity. I. A rapid unidirectional lyphocyte instructed pathway. J. Exp. Med. 154:892-906.

24. Rothberger, H., T. S. Zimmerman, H. L. Spiegleberg, and J. H. Vaughan. 1977. Leukocyte procoagulant activity. Enhancement of production 'in vitro' by IgG and antigen-antibody complexes. J. Clin. Invest. 59:549-557.

25. Mulfelder, T. W., J. Niemetz, D. Kreutzer, D. Beebe, P. A. Ward, and S. I. Rosenfeld. 1979. C5 chemotactic fragment induces leukocyte production of tissue factor activity: A link between complement and coagulation. J. Clin. Invest. 63:147-150.

26. Cole, E. H., J. Schulman, M. Urowitz, E. Keystone, C. Williams, and G. H. Levy. 1985. Monocyte procoagulant activity in glomerulonephritis associated with systemic lupus erythematosis. J. Clin. Invest. 75:861-868.

27. Francis, S. E., D. E. Joshua, T. Exner, and H. Kronenberg. 1985. Monoclonal antibodies to human F VIII R Ag and F VIII C. Pathology. 17:579-585.

28. Carson, S. D., S. E. Ross, R. Bach, and A. Guha. 1987. Im- munopurification of human tissue factor using an inhibitory monoclonal antibody. Blood. 70:490-493.

29. Yam, L. T., C. Y. Li, and W. H. Crosby. 1971. Cytochemical identification of monocytes and granulocytes. Am. J. Clin. Pathol. 55:283-290.

30. Lowry, O. H., N. J. Rosenbrough, A. L. Farr, and R. J. Randall. 1951. Protein measurement with the Folin phenol reagent. J. Biol. Chem. 193:265-275.

31. Thomson, N. M., J. Moran, I. J. Simpson, and D. K. Peters 1976. Defibrination with Ancrod in nephrotoxic nephritis in rabbits. Kidney Int. 10:343-347.

32. Pollack, V. E., H. I. Glueck, M. A. Weiss, A. Lebron-Berges, and M. A. Miller. 1982. Defibrination with Ancrod in glomerulonephritis. Effect on clinical and histologic findings and on blood coagulation. Am. J. Nephrol. 2:195-207.

33. George, C. R. P., W. F. Clark, and J. S. Cameron. 1975. The role of platelets in glomerulonephritis. Adv. Nephrol. 5:19-65.

34. Hopper, K. E., C. L. Geczy, and W. A. Davies. 1981. A mechanism of migration inhibition in delayed type hypersensitivity reactions. I. Fibrin deposition on the surface of elicited peritoneal macrophages 'in vivo'. J. Immunol. 126:1032-1058.

35. Geczy, C. L., and K. E. Hopper. 1981. A mechanism of migration inhibition in delayed-type hypersensitivity reactions. II. Lymphokines promote procoagulant activity of macrophages 'in vitro'. J. Immunol. 126:1059-1065.

36. Zacharski, L. R., R. Rosenstein, and P. G. Phillips. 1974. Concanavalin A inhibition of tissue factor (thromboplastin) activity. Blood. 44:783-787.

37. Nemerson, Y. 1968. The phospholipid requirement of tissue factor in blood coagulation. J. Clin. Invest. 47:72-80.

38. Otnaess, A. B., H. Prydz, E. Bjørklid, and A. Berre. 1972. Phospholipase $\mathrm{C}$ from Bacillus cereus and its use in studies of tissue thromboplastin. Eur. J. Biochem. 27:238-243.

39. Colucci, M., G. Balconi, R. Lorenzet, A. Pietra, D. Locati, M. B. Donati, and N. Semeraro. 1983. Cultures human endothelial cell generate tissue factor in response to endotoxin. J. Clin. Invest. 71:1893-1896.

40. Bevilacqua, M. P., J. S. Pober, G. R. Majear, R. S. Cotran, and M. H. Gimbrone. 1984. Interleukin I induces biosynthesis and cell surface expression of procoagulant activity in human vascular endothelial cells. J. Exp. Med. 160:618-623. 